\title{
LIGHT VEHICLE MODEL FOR DYNAMIC CAR SIMULATOR
}

\author{
Alessio Pieroni ${ }^{1}$, Claudio Lantieri ${ }^{2}$, Hocine Imine ${ }^{3}$, Andrea Simone ${ }^{4}$ \\ 1,2,4 School of Architecture and Engineering, University of Bologna, Italy \\ ${ }^{3}$ Laboratory for Road Operations, Perception, Simulators and Simulations; French Institute of Science \\ and Technology for Transport, Spatial Planning, Development and Networks, France
}

Submitted 22 April 2015; resubmitted 8 June 2015, 16 July 2015; accepted 25 August 2015

\begin{abstract}
Driving simulators have been becoming little by little a suitable tool oriented to improve the knowledge about the domain of driving research. The investigations that can be conducted with this type of tool concern the driver's behaviour, the design/control of vehicles, testing assistance systems for driving and the roadway infrastructure's impact. The benefits of simulation studies are many: lack of any real risk to users, reproducible situations, time savings and reduced testing costs. In addition, their flexibility allows to test situations that do not exist in reality or at least they rarely and randomly exist. The topic of the present work concerns the development of a brand new dynamic model for an existing car simulator owned by LEPSIS laboratory (Laboratoire d'Expliotation, Perception, Simulateurs et Silulations - Laboratory for Road Operations, Perception, Simulators and Simulations) belonging to COSYS (COmposants et SYStems), which is a department of IFSTTAR institute (Institut Français des Sciences et Technologies des Transports, de l'Aménagement et des Réseaux - French Institute of Science and Technology for Transport, Spatial Planning, Development and Networks) site. Once uses and advantages of driving simulators are listed and described, imperfections and limitations of the existing driving vehicle model belonging to the two Degrees of Freedom (DoF) driving simulator of the laboratory are highlighted. Subsequently, structure of the brand new vehicle model, designed by means of Matlab Simulink software, are illustrated through the theoretical framework. Since the vehicle model must refer to a real one, an instrumented Peugeot 406 has been chosen because all its technical features are provided and inserted both on the present model and Prosper/Callas 4.9 by OKTAL software to create a highly sophisticated and accurate virtual version of the commercial car. The validation of this new vehicle model is performed, where the results returned by several different driving scenarios are compared with the ones provided by Prosper software. All the scenarios are simulated with both existing and new vehicle model uploaded in the driving simulator, and the outputs are subsequently compared with the ones returned by Prosper in order to demonstrate the improvements done. Finally, being the number of outputs provided by the new model definitively higher with respect to previous one, additional validations concerning the further results are accomplished.
\end{abstract}

Keywords: dynamic driving simulator; light vehicle modelling; car dynamics; tire-pavement interaction; cornering stiffness; Burckhardt tire model; Prosper/Callas 4.9 by OKTAL.

\section{Introduction}

Driving simulators are efficient and innovative tools, which properly allow achieving complex tasks at a relatively low costs. These ones offer many advantages over reality when studying driving behaviour and they represent an efficient alternative to test track evaluations, for instance, performed in situ by means of instrumented vehicles. The application's field for driving simulators is wide and diversified. The most impressive and sophisticated ones are developed by car manufacturers (Yasuno et al. 2014; Fang et al. 2014) on purpose to study the dynamics of vehicles and the validation of their com- ponents or to test assistance systems (Daily, Bevly 2004; Chung et al. 2004). In contrast, universities and research institutes, depending on the budget, use simpler and, as in this case, low cost simulators in order study the behaviour of drivers and other road users, the impact of new regulations and evaluation of road design solutions. Driving simulators indeed allow testing and comparing different existing or new road configurations or equipment (Arioui et al. 2011). Thus, they allow to determine how road design solutions are perceived and understood by the drivers, and which driving behaviour they generate. The managers of road networks are particularly

Corresponding author: Claudio Lantieri

E-mail: claudio.lantieri2@unibo.it 
interested in the acceptance of these solutions by the users, in their impacts on the speed and the side position of vehicles, or still in their impact on traffic safety (Vienne et al. 2014). Moreover, since road safety is a matter of driver, infrastructure and vehicle, driving simulators represent a powerful way to perform road safety investigations (on existing or brand new paths) provided that the three main actors are all involved within the tool: for instance black spots along real roads where operating speed overcomes design speed could by virtually generated and analysed by the driving simulator (De Luca et al. 2012) instead of investigating them in situ. The same applies to study the impact of roadway alignment consistency for travel safety in context with current operating speeds (Dell'Acqua, Russo 2010, 2011). Beside the wide application field it is allowed to mention multiple advantages coming from driving simulators' exploitation.

Control, reproducibility, and standardization of the driving scenarios: It is possible to manipulate traffic and weather conditions, to test infrastructure's agents performance (e.g. adding or removing traffic lights from a junction). Tests can be reproduced all times needed with the great advantage of not stopping traffic service and finally using simulators, participants in different physical locations can drive under the exact same conditions. This is beneficial for creating standardized driving tests and reproducible research results (De Winter et al. 2012).

Ease of traffic and vehicle data collection: Driving simulators can measure performance accurately, efficiently and, as in the present case, in real time with sampling time of $0.001 \mathrm{~s}$. With a real vehicle, it is much more difficult to obtain proper and exhaustive measurement data. Vehicle model updated within the simulator deeply biases car dynamics and behaviour, so data collection depends mainly on its suitability. Furthermore, the simulation software can supply such information since it manages the movements of the vehicle driven by the participants and as well as the actions of the various autonomous agents populating the scene (Vienne et al. 2014).

Testing dangerous driving conditions in absolute safe way: This advantage is of paramount importance for road safety investigations because hazardous situations are rare and random events in reality and these aspects make this task cumbersome and obviously extremely dangerous for participants. Contrarily, driving simulator can reproduce whatever dangerous conditions (e.g. loss of adherence (Denoual et al. 2010), pre- accident driver's behaviour (Guzek et al. 2006) without jeopardizing people safety.

Novel opportunity for feedback and instruction: Simulators offer the opportunity for feedback and instruction that is not easily achieved in real vehicles. For example, it is possible to freeze, reset, or replay a scenario. Feedback and instructions can be delivered in other modalities besides speech, such as visual overlays to highlight critical features in the environment (De Winter et al. 2012).
Easy scripting of non-existing road features: Simulators allow creating virtual environments supported by the technical information, which describe the infrastructure (e.g., alignment, cross section). It can be the mock-up of a real environment or that of a future road project. It is possible to add or modify road features on purpose to evaluate new road design solutions (Vienne et al. 2014), new methodology for the management of road safety and new methods to analyse road design consistency (Dell'Acqua 2015).

Once the application of driving simulator is justified, it is fundamental to validate it in order to verify the acceptable similarity between virtual and real experiences. Driving simulator's performance is affected by physical, perceptual, and behavioural fidelities, which depend on visual, noise and motion restitution. Another aspect-biasing simulator's quality is the vehicle model updated within its software interface. The existing old vehicle model was pretty rough and inaccurate. First of all it calculates the vehicle motion according to pure rolling motion law, thus it totally neglects wheel's sliding. Furthermore, the vehicle lateral acceleration is estimated as the ratio of the car's velocity squared and radius of curvature. Moreover, the yaw rate is computed as the car's velocity over radius of curvature. Finally, the pitch angle comes from a motorbike model, thus totally inappropriate for light vehicle dynamics investigation. On the contrary, the brand new model is more appropriate and complex, providing more accurate results. A correct vehicle model is fundamental for the estimations, diagnosis and control of vehicle. To analyse the dynamics of vehicles, the equation of motions must be known and the physical interactions among vehicle's subsystems must be reported in a mathematical equations form according to rigorous physical approach (Imine et al. 2011). During its motion, the vehicle is subject to moments and forces of different origins that affect many parts of its structure. The vehicle motion is mainly obtained by the interaction between the tires and the road. The complete model is edited by means of Matlab Simulink and validated by Prosper/Callas 4.9 by OKTAL: it is a software concerning the simulation of vehicles' dynamics, 3D, non-linear, able to describe the behaviour of till the total loss of friction. It can model the vehicle having from 2 to 10 axis, with and without trailer. The suspensions can have all existing geometries, heat and electrical propulsion with whatever transmission scheme. The vehicles can ride even plans or 3D grounds with whatever adhesion condition. The user can perform programmed tests or entirely parameterized simulations, in postponed or real time. The car can be controlled by open or closed loop thanks to parameterized pilot. Literature offers many examples of different light vehicle models depending on research's goals (ASTM E1170-97:2012; Imine 2003; Enache 2008).

\section{Theoretical Framework}

The proposed dynamic vehicle model is nonlinear. The kinematic elements can greatly influence the vehicle dynamic behaviour. This is due to the existing intercon- 
nection between different parts of the vehicle. Due to the complexity of a complete vehicle, the model is limited to four interconnected subsystems: the chassis, the suspensions, the wheels and their interaction with the ground, the driver controls. The chassis is treated as an unconstrained body in the space so it contains six Degrees of Freedom (DoF); by introducing a reference system consistently integrated with vehicle body $R_{c}\left(G, X_{C}\right.$, $\left.Y_{C}, Z_{C}\right)$, the chassis counts three DoFs for translations along the longitudinal (surge), lateral (sway) and vertical (heave) axis and three for rotations about longitudinal (roll), lateral (pitch) and vertical (yaw) axis; the origin of the three axis is the vehicle Centre of Gravity $(\mathrm{CoG})$. The equations of motion of the chassis are obtained by applying the fundamental principles of classical physics. This leads to three ordinary differential equations for the translational motion of the CoG and three ordinary differential equations for the rotation. The transformation matrix $T_{r}$ permits the passage from the absolute reference system $R_{0}\left(0, X_{0}, Y_{0}, Z_{0}\right)$ to the integrated one. The chassis is connected to the ground by means of a system of suspensions and wheels.

For tires' modelling a new frame system, wheelfixed having its origin matching with tire-pavement contact point, is introduced (Fig. 1). Within this point three forces are developed: longitudinal force $F_{x}$, lateral force $F_{y}$ and vertical force $F_{z}$. To calculate vertical wheels' forces, expressions provided by Imine (Imine et al. 2011) are taken into account. Longitudinal wheel's force is calculated according to Coulomb's principle. It's so strictly linked to the vertical force by longitudinal adhesion coefficient $\mu_{i}$. The model employed to estimate the longitudinal adhesion coefficient is the one of Burckhardt. The set of coefficients contained in the formula describes the road condition and they are available in literature (Dousti et al. 2015). The longitudinal sliding of the $i$-th wheel $\lambda_{x_{i}}$ is calculated according to Imine, expressed both for braking and acceleration phases. $\omega_{i}$ represents the tire spin velocity of the $i$-th wheel, $R$ is the wheel's radius and $v_{i}$ is the longitudinal velocity the CoG of the $i$-th wheel (2003). When the vehicle is in motion, a deviation between its longitudinal axis and its motion direction may be produced. This deviation is characterized by the sideslip angle $\beta . \alpha$ represents the wheel slip angle whereas: the relation to express $\alpha$ is reported by Imine (2003). Shraim et al. (2006) assert that for small values of $\alpha$, in particular for lateral accelerations below $4 \mathrm{~m} / \mathrm{s}^{2}$, tire's lateral force $F_{y}$ can be expressed as the product of wheel slip angle and tire's cornering stiffness $C_{y}$. By simulating a leftwards chicane manoeuvre with Prosper, it is evident how for lateral acceleration (Fig. 2) lower than above-mentioned threshold, the cornering stiffness is not constant (Fig. 3).

Cornering stiffness is not constant while negotiating the chicane manoeuvre. The value assumed before and after the steering action corresponds to the Cornering stiffness nominal value $C_{y_{0}}$. It is perturbed with a certain trend according to tires vertical forces variations. It is evident a strict connection with tires' vertical load. This relationship is important in the sense that,

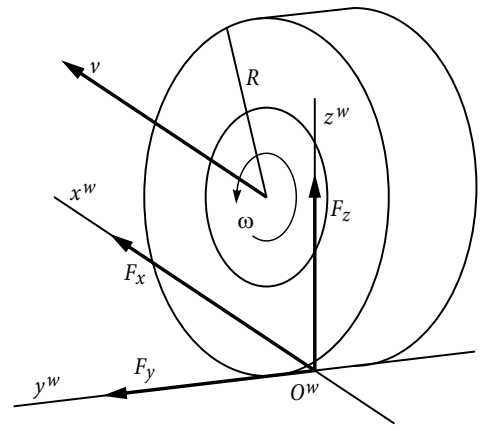

Fig. 1. Tire’s model

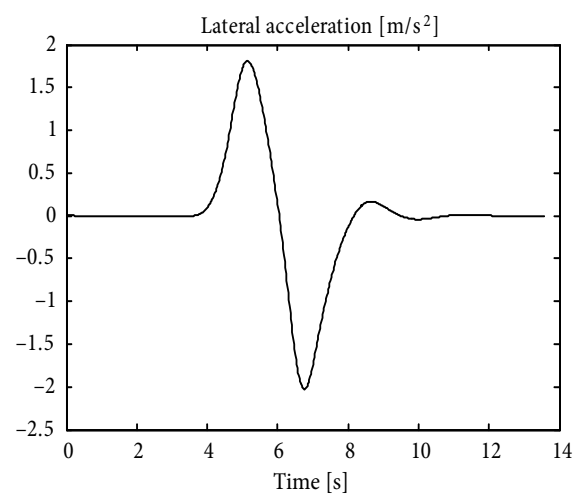

Fig. 2. Lateral acceleration - chicane
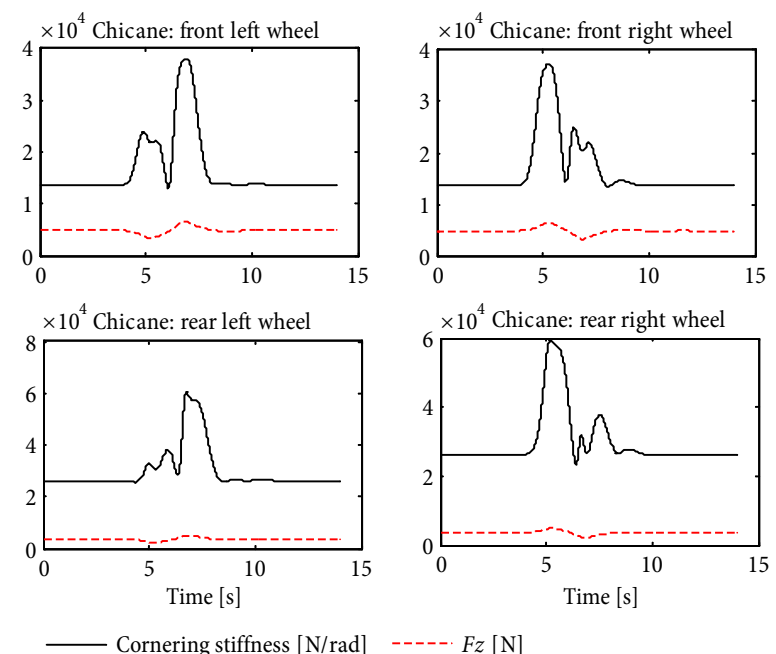

Fig. 3. Cornering Stiffness and tires' vertical forces - chicane

during cornering, the tire load of the outer wheel will increase whereas the inner wheel load will decrease. Due to the nonlinear dependence of cornering stiffness on tire load, the change in cornering stiffness at the outer wheel is exceeded in absolute value by the change at the inner wheel. Both cornering stiffness and vertical tire loads largely varies for all the four wheels while performing a change of lane, whereas in a straight stretch driven with constant speed they are not subjected to variation, because relevant changes of $F_{z}$ don't occur. To sum up, the classic formula to calculate tire's lateral force $F_{y_{i}}=C_{y_{i}} \cdot \alpha_{i}$ has been implemented in the following way: 


$$
\begin{aligned}
& F_{y_{i}}=\left(C_{y_{0 i}}+\left(\frac{F z_{i}-F z_{0 i}}{F z_{0 i}}\right) \cdot C_{y_{0 i}}\right) \cdot \alpha_{i} . \\
& \left(F_{z_{i}}-F_{z_{0}}\right) / F_{z_{0}} \text { is nothing but the relative increa- }
\end{aligned}
$$

se/drop of $i$-th tire's vertical load, which is relevant for accelerations and steering manoeuvre, whereas it is almost negligible for constant speed over straight trajectory. The wheel's force comes from the equilibrium of $C_{t}$. (transmission torque provided by the engine to the $i$-th wheels) $C_{b_{i}}$ (braking torque provided by braking system to the $i$-th wheel) and longitudinal tire forces time wheel's radius.

\section{Methodology}

Once all the theoretical frame is known, the complete vehicle model was created by means of Matlab Simulink software. The reference commercial vehicle on which the model is based is a Peugeot 406, instrumented by LCPC (Laboratoire Central des Ponts et Chaussées) of Nantes for investigations in situ about car dynamics and road profile estimation (Imine 2003), whose features concerning geometry, mass, suspensions, transmission system, aerodynamic, tires, engine, brakes and direction are available. The same data are used for Prosper/Callas 4.9 by OKTAL in order to build a virtual version of the Peugeot 406 as close as possible to the real one. Once the Prosper vehicle model is completed, simulations can be performed with the software and subsequently, by using the same inputs to reproduce the same scenario and manoeuvre, reproduced by the Matlab Simulink vehicle model. Thus, before updating driving simulator existing vehicle model, a first validation is done by comparing Prosper's outputs with the ones reached by Simulink model. The inputs, common for both platforms, are steering wheel angle, transmission torque, braking torque and longitudinal road profile. These simulated scenarios were chosen on purpose to enhance and to check all vehicle dynamics; they are a straight stretch (even and rough pavement), chicane, constant radius bend. Once a first validation took place, the brand new vehicle model is imported within the driving simulator's Simulink interface to replace the existing one. The dynamic driving simulator owed by LEPSIS (Fig. 4) was designed and built under VIGISIM project in 2009 to study various configurations of motion rendering and the impact of these variants on controllability and on simulator sickness. It presents two DoF: it allows the rendering of the longitudinal and yaw movements, ruled by specific motion cues algorithms. It presents a system of 5 projectors for the visual restitution and a system of 4 speakers for the sound restitution. In order to replace the lack of tire-pavement contact interface, a steering wheel's actuation system is installed to provide a feedback force for steering manoeuvres.

Fig. 4 depicts the virtual environment for the validation process. Three types of manoeuvres are simulated with both new and old vehicle model, and both validated with the aid of Prosper software to judge the reliability and the improvements done with respect to the past. The main difference with respect to previous case consists in the fact that now the driving controls come directly from a real person joining the simulation experience.

After that, the same inputs provided by the driver to the simulator are uploaded in Prosper in order to ride the same path and the outputs coming from the dynamic driving simulator and Prosper are finally compared. The three driving manoeuvres, all performed along the same virtual circuit, have been chosen on purpose to spotlight the many car motions. The manoeuvres are a straight stretch, an overtaking manoeuvre and riding two bends belonging to the virtual path.

\section{Validation Results}

The first comparison between new and old model considers an overtaking manoeuvre that is nothing but a double chicane: a leftwards first and a rightwards then. New model's results, compared to the ones returned by Prosper are definitively better with respect to old vehicle model ones. The yaw angels' values of new model's curve fits doubtless better Prosper data with respect to old model outputs (Fig. 5). Even lateral acceleration's plot confirms the higher accuracy of the new model (Fig. 6).

Despite the fact that the trend is similar for both new and old vehicle model, the accuracy of the maximum and minimum values is definitively better for the new one. Table 1 reports the relative errors of maximum and minimum values for both new and old vehicle mo-
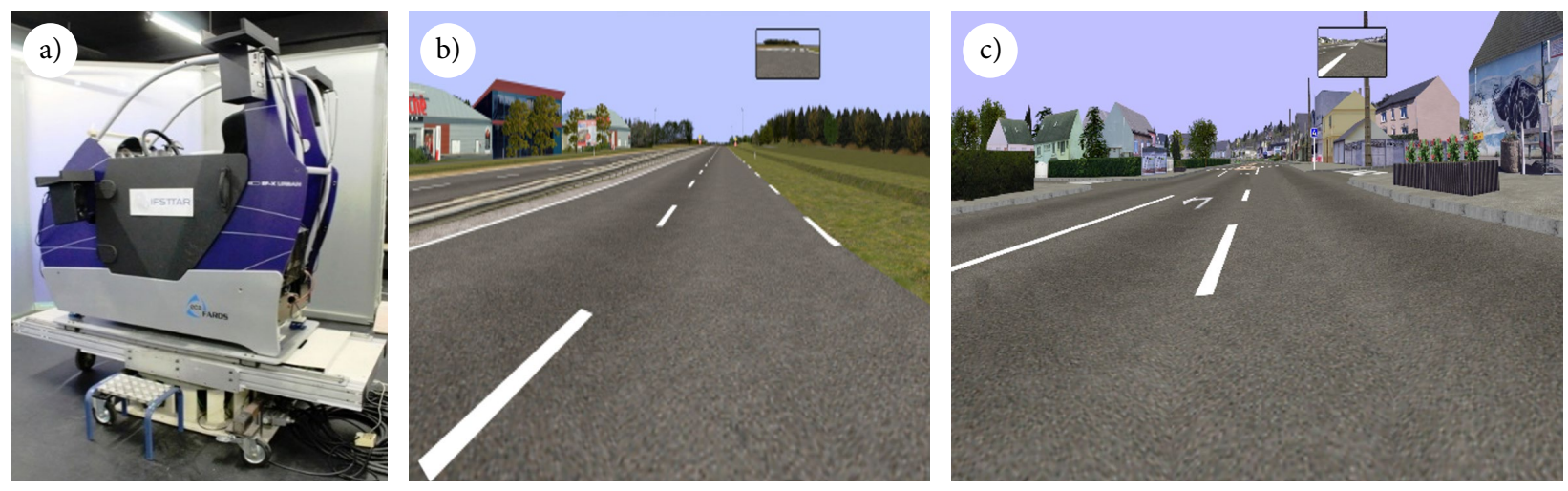

Fig. 4. Two DoF driving simulator (a), virtual environment (b, c) 
del: it is evident how relative errors for the new model are much more restrained.

Concerning yaw velocity, both models return reliable results (Fig. 7). The accuracy of car's sway is clearly better for new vehicle model, indeed since the beginning of the simulation old vehicle's data start diverging (Fig. 8).

Achieving the same overtaking manoeuvre, $F_{y}$ calculated by using the brand new Eq. (1), provides reliable results (Fig. 9). Fig. 10 depicts roll angle's values during the overtaking manoeuvre: the trend is the same for both curves, however a driving simulator's overestimation is exhibited. Concerning the straight stretch scenario, a slight acceleration phase is followed by a hard braking phase. Pitch angles sketch a very close shape although Prosper's values are constantly higher due to different initial conditions (Fig. 11) (DS stands for Driving Simulator).

Fig. 12 sketches tire's vertical forces of the model: although always a bit lower, DS data properly fit Prosper's data. Longitudinal wheel forces curves (Fig. 13) are very close each other till the maximum braking pressure occurs where the front wheels, subjected to an elevated braking torque, deeply diverge: this is due to the fact that Prosper uses the Pacejka adhesion model (Pacejka 1989) contrary
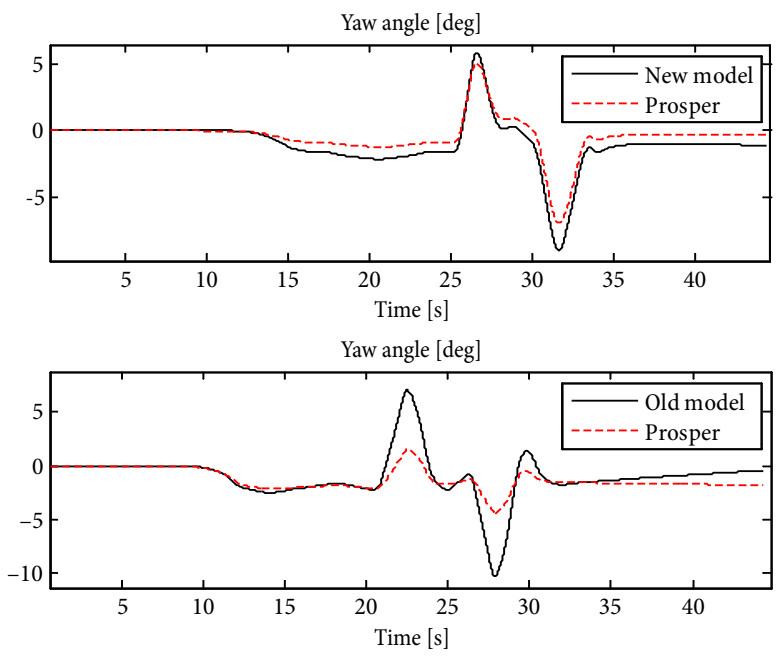

Fig. 5. Yaw angle - overtaking
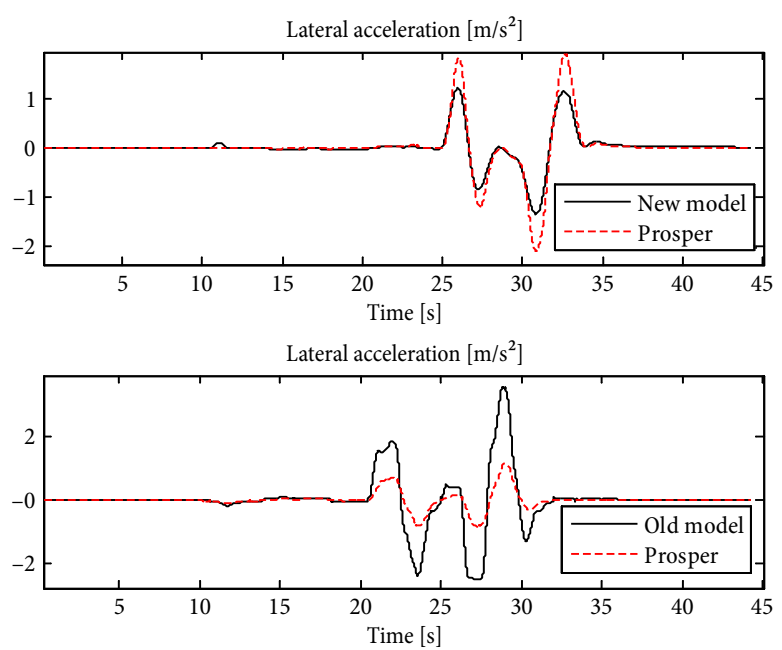

Fig. 6. Lateral acceleration - overtaking
Table 1. Relative errors for max and min values for yaw angle and lateral acceleration - overtaking

\begin{tabular}{|c|c|c|c|}
\hline & & Yaw angle & $\begin{array}{c}\text { Lateral } \\
\text { acceleration }\end{array}$ \\
\hline \multirow{2}{*}{$\begin{array}{l}\text { New } \\
\text { vehicle } \\
\text { model }\end{array}$} & $\begin{array}{l}\text { Relative error for } \\
\text { maximum values [\%] }\end{array}$ & 15.39 & 35.53 \\
\hline & $\begin{array}{l}\text { Relative error for } \\
\text { minimum values [\%] }\end{array}$ & 29.23 & 36.36 \\
\hline \multirow{2}{*}{$\begin{array}{l}\text { Old } \\
\text { vehicle } \\
\text { model }\end{array}$} & $\begin{array}{l}\text { Relative error for } \\
\text { maximum values [\%] }\end{array}$ & 1159.3 & 209.17 \\
\hline & $\begin{array}{l}\text { Relative error for } \\
\text { minimum values [\%] }\end{array}$ & 369.23 & 146.29 \\
\hline
\end{tabular}

to the present model which uses Burckhardt's one: thus in case of relevant wheel sliding the two model strongly diverge each other. Finally, driving the vehicle over an irregular pavement at constant speed $(70 \mathrm{~km} / \mathrm{h})$ along a straight path, whose roughness is estimated by Lengthways Profile Analyser (APL) apparatus and, the vertical displacements of wheels properly fits the Prosper's curve (Fig. 14). Even the curve of the vertical displacement of the CoG of the chassis returns suitable results (Fig. 15).
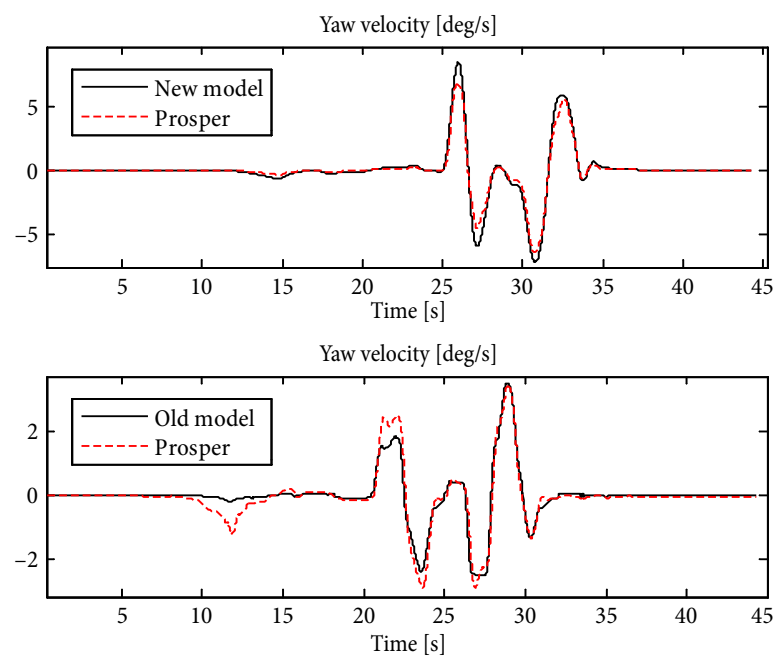

Fig. 7. Yaw velocity - overtaking
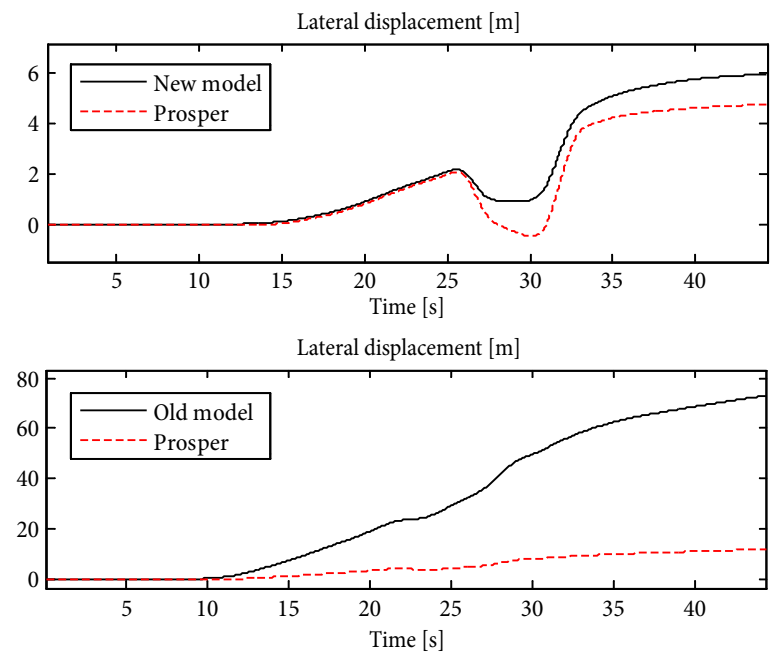

Fig. 8. Lateral displacement - overtaking 

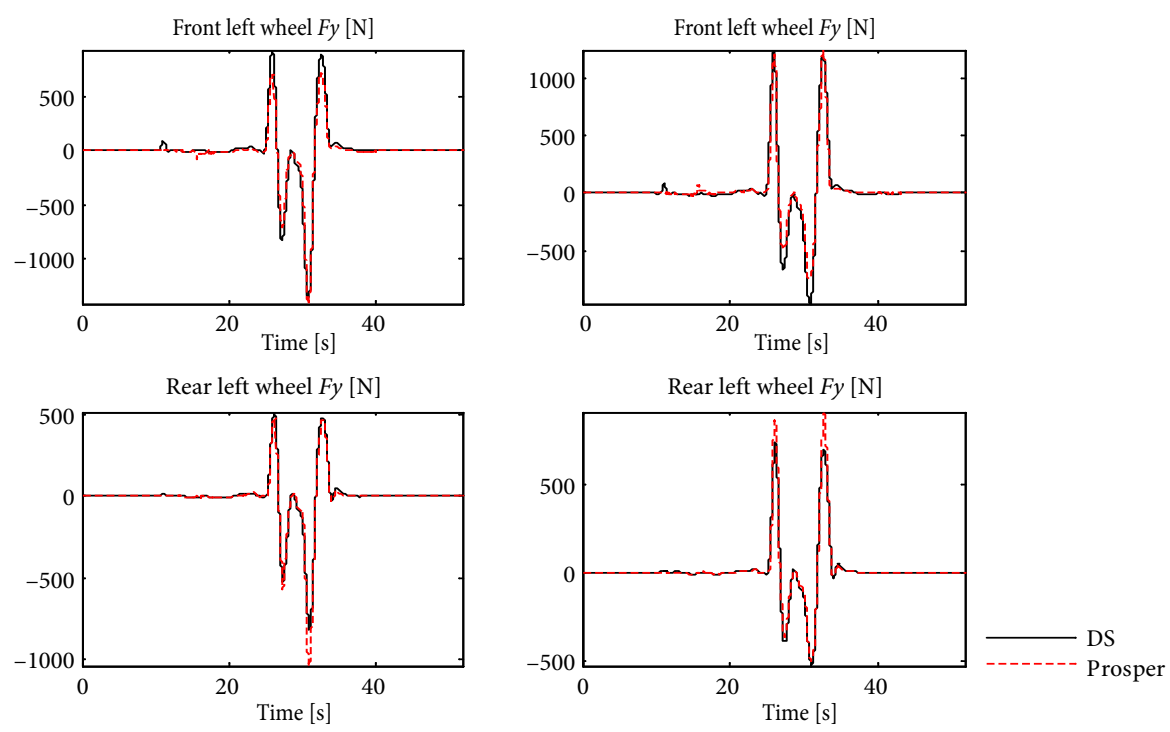

Fig. 9. Tire's lateral force - overtaking

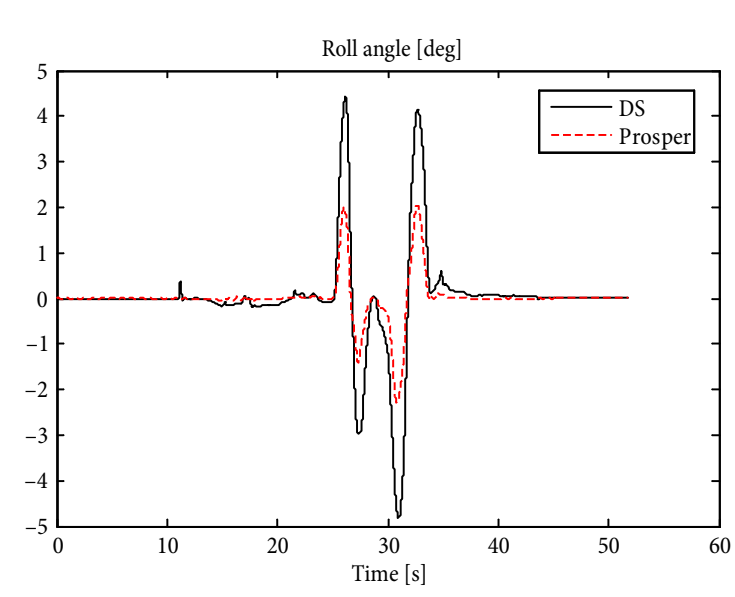

Fig. 10. Roll angle - overtaking

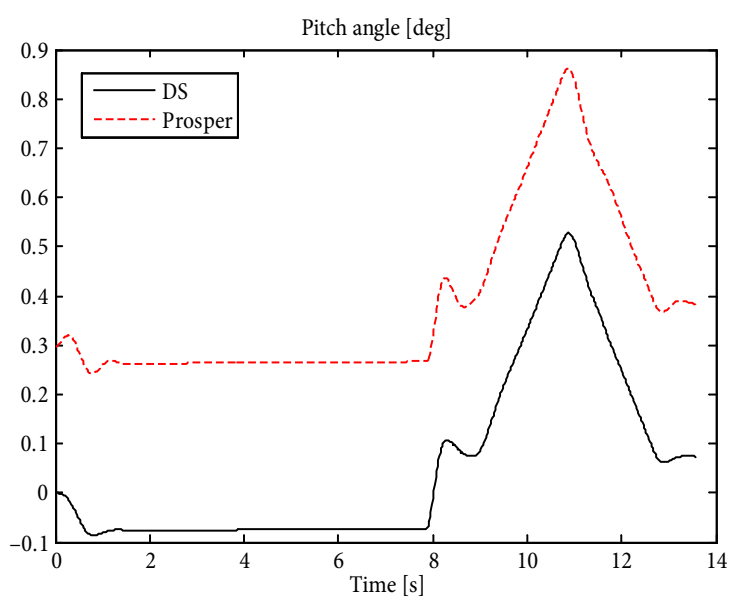

Fig. 11. Pitch angle - straight stretch
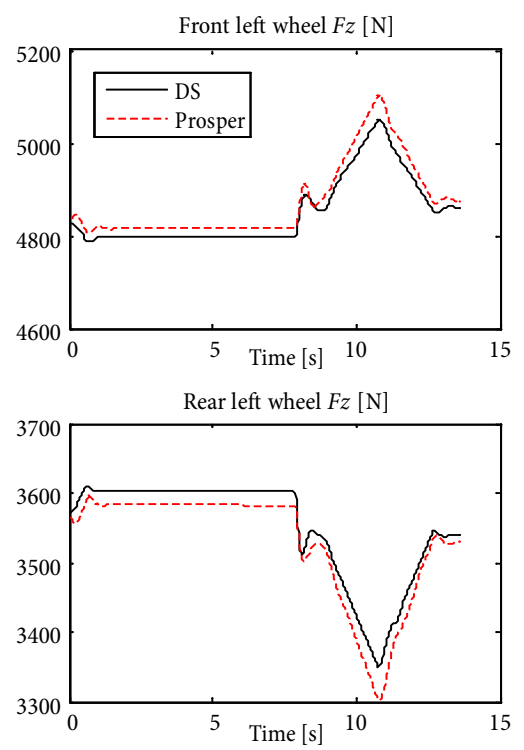

Fig. 12. Tires' vertical forces - straight stretch
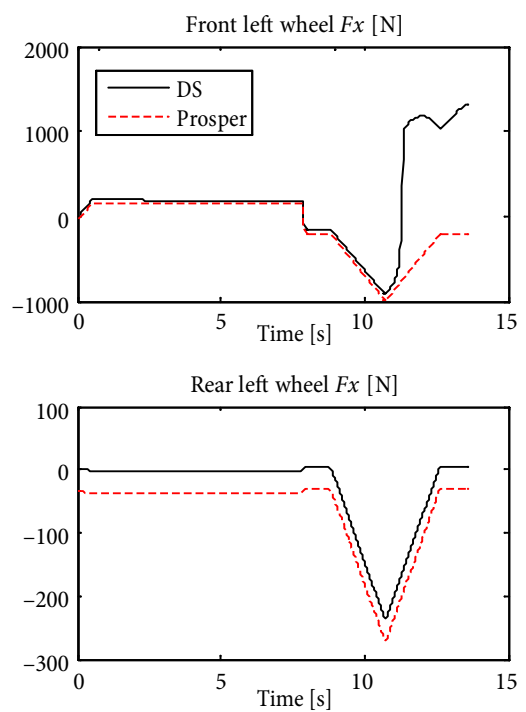

Fig. 13. Tires' longitudinal forces - straight stretch 


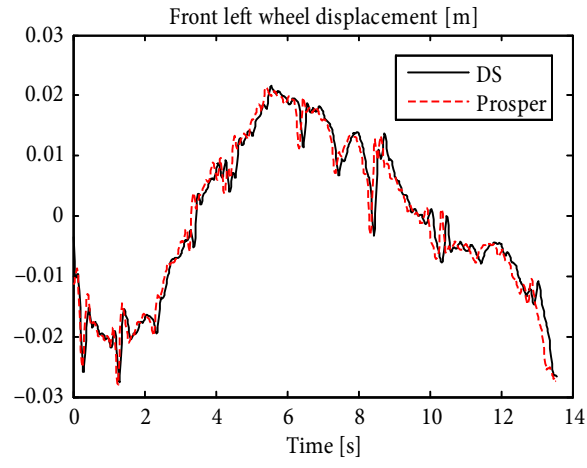

Fig. 14. Wheel's vertical displacement

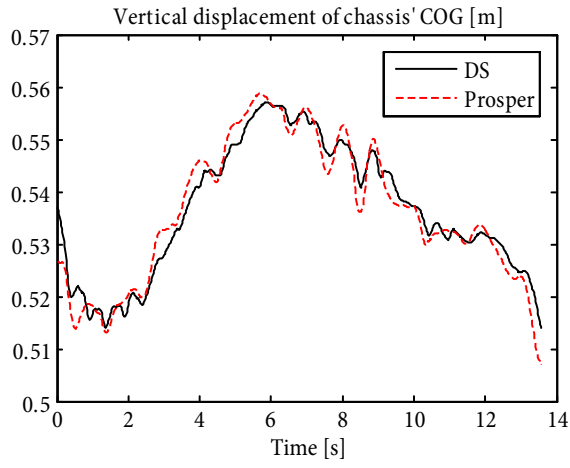

Fig. 15. Vehicle's vertical displacement

Table 2. New vehicle model's outputs

\begin{tabular}{|c|c|c|c|c|c|}
\hline Roll acceleration & $\ddot{\vartheta}$ & Roll velocity & $\dot{\vartheta}$ & Roll angle & $\vartheta$ \\
\hline Pitch acceleration & $\ddot{\phi}$ & Pitch velocity & $\dot{\phi}$ & Pitch angle & $\phi$ \\
\hline Yaw acceleration & $\ddot{\psi}$ & Yaw velocity & $\dot{\psi}$ & Yaw angle & $\psi$ \\
\hline Wheels vertical acceleration & $\ddot{z}_{i}$ & Wheels vertical velocity & $\dot{z}_{i}$ & Wheels vertical displacement & $z_{i}$ \\
\hline CoG vertical acceleration & $\ddot{z}$ & CoG vertical velocity & $\dot{z}$ & CoG vertical displacement & $z$ \\
\hline Wheel vertical force & $F_{z_{j}}$ & Wheel lateral force & $F_{y_{j}}$ & Wheel longitudinal force & $F_{x_{j}}$ \\
\hline Longitudinal vehicle acceleration & $a_{x}$ & Lateral vehicle acceleration & $a_{y}$ & Longitudinal vehicle velocity & $v_{x}$ \\
\hline Lateral vehicle velocity & $v_{y}$ & Vehicle surge & $X$ & Vehicle sway & Y \\
\hline Longitudinal adhesion coefficient & $\mu_{x i}$ & Longitudinal wheel sliding & $\lambda_{x i}$ & Longitudinal wheel velocity & $v_{x i}^{w}$ \\
\hline Side slip velocity & $\dot{\beta}$ & Side slip angle & $\beta$ & Wheel slip angle & $\alpha_{i}$ \\
\hline Longitudinal aerodynamic force & Faero $_{x}$ & & & & \\
\hline
\end{tabular}

\section{Conclusions}

The brand new dynamic vehicle model has been designed in order to fully accomplish simulation goals and returning as much as possible results from a vehicle riding a virtual path. First of all, due to the completeness of the model, a much greater number of outputs can be provided with respect to the existing one, and thanks to this, it will be possible to thoroughly study whatever driving scenario. The total number of outputs is listed hereinafter. Old vehicle model provided only 7 of those ones $\left(X, Y, \vartheta, \psi, \dot{\psi}, a_{x}, a_{y}\right)$.

Besides the elevated number of outputs, even the accuracy, at least of the common ones, has been improved. An essential enhancement is the introduction of wheel's sliding and slipping, thus the adhesion model, which first was totally neglected: it is well established how road friction knowledge is a crucial topic for road safety investigations and simulation's fidelity. Beside this, the brand new model still present some constrains. First of all, Burkhardt law, by the comparison with Prosper, is valid only along the first branch of the equation curve, thus for small wheels' sliding, where it well approximates Pacejka's formula. This means that a hard braking, leading to relevant wheels' sliding, biases the results. Thus, it is important to try implementing adhesion model by introducing Pacejka's formula, even though it has its own limits as well.

\section{References}

Arioui, H.; Hima, S.; Nehaoua, L.; Bertin, R. J. V.; Espié, S. 2011. From design to experiments of a 2-DOF vehicle driving simulator, IEEE Transactions on Vehicular Technology 60(2): 357-368. http://doi.org/10.1109/TVT.2010.2090675

ASTM E1170-97:2012. Standard Practices for Simulating Vehicular Response to Longitudinal Profiles of Traveled Surfaces.

Chung, T.; Yi, K.; Kim, J. 2004. Evaluation of vehicle dynamic control systems using a vehicle simulator, in AVEC'04: 7th International Symposium on Advanced Vehicle Control, 23-27 August 2004, HAN University, Arnhem, The Netherlands, $175-180$.

Daily, R.; Bevly, D. M. 2004. The use of GPS for vehicle stability control systems, IEEE Transactions on Industrial Electronics 51(2): 270-277. http://doi.org/10.1109/TIE.2004.824851

De Luca, M.; Dell'Acqua, G.; Lamberti, R. 2012. Road safety analysis using operating speeds: case studies in Southern Italy, Procedia - Social and Behavioral Sciences 53: 702-710. http://doi.org/10.1016/j.sbspro.2012.09.920

De Winter, J. C. F.; Van Leeuwen, P. M.; Happee, R. 2012. Advantages and disadvantages of driving simulators: a discussion, in Proceedings of Measuring Behavior 2012, 28-31 August 2012, Utrecht, The Netherlands, 47-50.

Dell'Acqua, G. 2015. Modeling driver behavior by using the speed environment for two-lane rural roads, Transportation Research Record: Journal of the Transportation Research Board 2472: 83-90. http://doi.org/10.3141/2472-10

Dell'Acqua, G.; Russo, F. 2011. Road performance evaluation using geometric consistency and pavement distress data, 
Transportation Research Record: Journal of the Transportation Research Board 2203: 194-202.

http://doi.org/10.3141/2203-24

Dell'Acqua, G.; Russo, F. 2010. Speed factors on low-volume roads for horizontal curves and tangents, The Baltic Journal of Road and Bridge Engineering 5(2): 89-97. http://doi.org/10.3846/bjrbe.2010.13

Denoual, T.; Mars, F.; Petiot, J.-F.; Reymond, G.; Kemeny, A. 2010. Drivers' perception of simulated loss of adherence in bends, in Proceedings of the Driving Simulation Conference Europe 2010, 9-10 September 2010, Paris, France, 43-53.

Dousti, M.; Başlamışlı, S. Ç.; Onder, T.; Solmaz, S. 2015. Design of a multiple-model switching controller for ABS braking dynamics, Transactions of the Institute of Measurement and Control 37(5): 582-595. http://doi.org/10.1177/0142331214546522

Enache, N. M. 2008. Assistance préventive à la sortie de voie. Thèse présentée et soutenue publiquement le 17 Novembre 2008 pour l'obtention du Doctorat de l'Université d'ÉvryVal-d'Essonne (spécialité automatique). 307 p. (in French).

Fang, Z.; Colombet, F.; Collinet, J.-C.; Kemeny, A. 2014. Roll tilt thresholds for 8 DOF driving simulators, in New Developments in Driving Simulation Design and Experiments: Driving Simulation Conference Europe 2014 Proceedings, 4-5 September, Paris, France, 16.1-16.7.

Guzek, M.; Jurecki, R.; Lozia, Z.; Stańczyk, T. L. 2006. Comparative analyses of driver behavior on the track and in virtual environment, in Proceeding of Driving Simulation Conference 2006, 4-6 October 2006, Paris, France, 221-232.

Imine, H. 2003. Observation d'états d'un véhicule pour l'estimation du profil dans les traces de roulement. Thèse de l'Université de Versailles Saint. 143 p. (in French).

Imine, H.; Fridman, L.; Shraim, H.; Djemai, M. 2011. Sliding Mode Based Analysis and Identification of Vehicle Dynamics. Springer Berlin Heidelberg. 127 p. http://doi.org/10.1007/978-3-642-22224-5

Pacejka, H. 1989. Modeling of the Pneumatic Tyre and its Impact on Vehicle Dynamic Behavior. Technical Report. Vehicle Research Laboratory, Delft University of Technology, The Netherlands.

Shraim, H.; Ananou, B.; Fridman, L.; Noura, H.; Ouladsine, M. 2006. Sliding mode observers for the estimation of vehicle parameters, forces and states of the center of gravity, in Proceedings of the 45th IEEE Conference on Decision and Control, 13-15 December 2006, San Diego, CA, US, 1635-1640. http://doi.org/10.1109/CDC.2006.376777

Vienne, F.; Caro, S.; Désiré, L.; Auberlet, J. M.; Rosey, F.; Dumont, E. 2014. Driving simulator: an innovative tool to test new road infrastructures, in Transport Research Arena 2014, 14-17 April 2014, Paris, France, 1-10.

Yasuno, Y.; Kitahara, E.; Takeuchi, T.; Tsushima, M.; Saitou, H.; Imamura, M.; Ueno, E. 2014. Nissan's new high performance driving simulator for vehicle dynamics performance \& man-machine interface studies, in New Developments in Driving Simulation Design and Experiments: Driving Simulation Conference Europe 2014 Proceedings, 4-5 September 2014, Paris, France, 44.1-44.2. 